\title{
Synthesis and Thermoelectric Properties of $\left(\mathrm{La}_{1-\mathrm{z}} \mathrm{Nd}_{\mathrm{z}}\right)_{0.8} \mathrm{Fe}_{4-\mathrm{x}} \mathrm{Co}_{\mathrm{x}} \mathrm{Sb}_{12}$ Skutterudites Ye-Eun Cha and Il-Ho Kim* \\ Department of Materials Science and Engineering, Korea National University of Transportation, Chungju 27469, Republic of Korea
}

\begin{abstract}
Type $\left(\mathrm{La}_{1-\mathrm{z}} \mathrm{Nd}_{\mathrm{z}}\right)_{0.8} \mathrm{Fe}_{4-\mathrm{x}} \mathrm{Co}_{\mathrm{x}} \mathrm{Sb}_{12}$ skutterudites were prepared by partial double filling with $\mathrm{La} / \mathrm{Nd}$ and charge compensation by substituting Co for Fe. The skutterudite phase was successfully synthesized using encapsulated melting, quenching, annealing and hot-pressing processes, but a small amount of the marcasite phase was identified. Partial filling within the filling fraction limit did not result in the formation of the (La,Nd) $\mathrm{Sb}_{2}$ phases detected in the fully-filled $\mathrm{La}_{1-\mathrm{z}} \mathrm{Nd}_{\mathrm{z}} \mathrm{Fe}_{4-\mathrm{x}} \mathrm{Co}_{\mathrm{x}} \mathrm{Sb}_{12}$ because that phase is generated when the $\mathrm{La} / \mathrm{Nd}$ partial filling exceeds the filling fraction limit. $\left(\mathrm{La}_{0.25} \mathrm{Nd}_{0.75}\right)_{0.8} \mathrm{Fe}_{4} \mathrm{Sb}_{12}$ showed the highest electrical conductivity of $2.32 \times 10^{5} \mathrm{~S} \mathrm{~m}^{-1}$ at $323 \mathrm{~K}$, and $\left(\mathrm{La}_{0.75} \mathrm{Nd}_{0.25}\right)_{0.8} \mathrm{Fe}_{3} \mathrm{CoSb}_{12}$ exhibited the largest Seebeck coefficient of $167 \mu \mathrm{V} \mathrm{K}^{-1}$ at $723 \mathrm{~K}$. The power factors and thermal conductivities of all the specimens were in the range of $1.43-2.59 \mathrm{~mW} \mathrm{~m}^{-1} \mathrm{~K}^{-2}$ and $2.05-3.95 \mathrm{~W} \mathrm{~m}^{-1} \mathrm{~K}^{-1}$, respectively, in the temperature range of $323-823 \mathrm{~K}$. $\left(\mathrm{La}_{0.25} \mathrm{Nd}_{0.75}\right)_{0.8} \mathrm{Fe}_{3} \mathrm{CoSb}_{12}$ showed the highest power factor of $2.59 \mathrm{~mW} \mathrm{~m}{ }^{-1} \mathrm{~K}^{-2}$ at $823 \mathrm{~K}$ and the lowest thermal conductivity of $2.05 \mathrm{~W} \mathrm{~m}^{-1} \mathrm{~K}^{-1}$ at $323 \mathrm{~K}$. Thus, $\left(\mathrm{La}_{0.25} \mathrm{Nd}_{0.75}\right)_{0.8} \mathrm{Fe}_{3} \mathrm{CoSb}_{12}$ exhibited a maximum dimensionless figure of merit $\left(Z T_{\max }\right)$ of 0.76 at $723 \mathrm{~K}$.
\end{abstract}

(Received April 4, 2019; Accepted April 24, 2019)

Keywords: thermoelectric, skutterudite, partial double filling, charge compensation

\section{INTRODUCTION}

The performance of thermoelectric materials is expressed by the dimensionless figure of merit, $Z T=\alpha^{2} \sigma \kappa^{-1} T$, where $\alpha$ is the Seebeck coefficient, $\sigma$ is the electrical conductivity, $\kappa$ is the thermal conductivity $\left(\kappa=\kappa_{\mathrm{E}}+\kappa_{\mathrm{L}}: \kappa_{\mathrm{E}}\right.$ and $\kappa_{\mathrm{L}}$ represent the contribution of carriers and phonons to the thermal conductivity, respectively), and $T$ is the absolute temperature [1-3]. To obtain higher $Z T$ values, thermoelectric materials should have a high power factor $\left(\mathrm{PF}=\alpha^{2} \sigma\right)$ and low thermal conductivity. To achieve higher PF values, the materials must have a large Seebeck coefficient and high electrical conductivity. However, these parameters are interdependent on the carrier concentration. Therefore, it is difficult to control each parameter independently because the thermal conductivity also increases as the electrical conductivity increases [4,5]. In 1994, Slack proposed the phonon-glass and electron-crystal (PGEC) concept, which likens thermal properties to amorphous structures and electrical properties to

- Ye-Eun Cha: 석사과정, Il-Ho Kim: 교수

*Corresponding Author: Il-Ho Kim

[Tel: +82-43-841-5387, E-mail: ihkim@ut.ac.kr]

Copyright (C) The Korean Institute of Metals and Materials crystalline structures [6]. Thermoelectric materials conforming to the PGEC concept include the $\mathrm{Bi}-\mathrm{Te}, \mathrm{Pb}-\mathrm{Te}$, and $\mathrm{Si}-\mathrm{Ge}$ systems, skutterudites, clathrates, etc. Among these materials, skutterudites are attractive because of their high conversion efficiency and concomitant low thermal conductivity and high electrical conductivity [2]. Skutterudites have the basic formula $8 \mathrm{MX}_{3}$ with two large voids in the unit cell. For a filled skutterudite, the thermal conductivity is reduced when the voids are filled with an atom (filler or rattler). Phonon scattering can be enhanced by the rattling effect of these filler atoms with the independent vibrations in the voids. Therefore, the reduced lattice thermal conductivity can result in improved thermoelectric performance [6,7].

Many studies have been conducted to improve the thermoelectric properties of n-type skutterudites. Attempts have been made to achieve higher $Z T$ values of filled n-type skutterudites $\mathrm{R}_{\mathrm{y}} \mathrm{Co}_{4} \mathrm{Sb}_{12}$ ( $\mathrm{R}$ : filling element and $\mathrm{y}$ : filling fraction) by maximizing the power factor through doping [8] and optimizing the fillers [9-11], and by reducing the thermal conductivity through nanostructuring [12,13] and phonon scattering [14,15]. p-Type skutterudites exhibit relatively low $Z T$ values compared to n-type skutterudites [14]. However, 
thermoelectric devices require both n-type and p-type materials with high stability and excellent performance. Decreasing the lattice thermal conductivity of p-type skutterudites by doping with various atoms and fillers [1618] has been studied, along with the use of substitutional solid solutions [19]. Double filling in the skutterudite structure is a very effective approach for reducing the lattice thermal conductivity, because each filler atom has a specific resonance frequency and acts as a phonon scattering center [7,20-22]. Among the filler atoms, rare-earth elements with heavier atomic masses can effectively reduce the lattice thermal conductivity by scattering phonons of lower frequencies due to their smaller ionic radii and lower resonance frequencies [7,20,23]. Therefore, double or multiple filling can cause greater phonon scattering, resulting in improved thermoelectric performance [22,24-26].

$\mathrm{R}_{\mathrm{y}} \mathrm{Fe}_{4} \mathrm{Sb}_{12}$ is a p-type filled skutterudite that is widely used $[23,27,28] .\left[\mathrm{Co}_{4} \mathrm{Sb}_{12}\right]$ is stable with 72 valence electrons, whereas $\left[\mathrm{Fe}_{4} \mathrm{Sb}_{12}\right]$ is unstable because it has only 68 valence electrons. Therefore, four electrons are required to stabilize the skutterudite phase [27], and the R-filled $\mathrm{R}^{4+}\left[\mathrm{Fe}_{4} \mathrm{Sb}_{12}\right]^{4-}$ form is possible. However, most elements used as fillers exist in the $\mathrm{R}^{2+}$ and $\mathrm{R}^{3+}$ valence states, leading to a lack of valence electrons [29]. Consequently, charge compensation is required and can be fulfilled by substituting $\mathrm{Co}$ or $\mathrm{Ni}$ into the Fe site [30]. Recently, some studies have reported that p-type skutterudites cannot be completely filled when the charge is compensated by substituting $\mathrm{Co}$ or $\mathrm{Ni}$ into the $\mathrm{Fe}$ site [3133]. In addition, completely double-filled and Co-substituted skutterudites produced $\mathrm{RSb}_{2}$ secondary phases because the double filling exceeded the filling fraction limit [34]. In this study, La/Nd-partially-double-filled and Co-substituted ptype $\left(\mathrm{La}_{1-\mathrm{z}} \mathrm{Nd}_{\mathrm{z}}\right)_{0.8} \mathrm{Fe}_{4-\mathrm{x}} \mathrm{Co}_{\mathrm{x}} \mathrm{Sb}_{12}$ skutterudites were prepared and their thermoelectric properties were examined.

\section{EXPERIMENTAL PROCEDURE}

La (purity 99.9\%, Kojundo), Nd (purity 99.9\%, Kojundo), Fe (purity 99.95\%, Cerac), Co (purity 99.95\%, Alfa Aesar), and $\mathrm{Sb}$ (purity $99.999 \%$, LTS) were weighed according to the stoichiometric compositions of $\left(\mathrm{La}_{1-\mathrm{z}} \mathrm{Nd}_{\mathrm{z}}\right)_{0.8} \mathrm{Fe}_{4-\mathrm{x}} \mathrm{Co}_{\mathrm{x}} \mathrm{Sb}_{12}(\mathrm{z}=$ $0.25,0.75$ and $\mathrm{x}=0,0.5,1)$ and melted in an evacuated quartz tube at $1323 \mathrm{~K}$ for $10 \mathrm{~h}$, followed by quenching in water. The resulting ingot was annealed at $873 \mathrm{~K}$ for $24 \mathrm{~h}$ for phase stabilization and homogenization, and then ground into a powder with a particle size of less than $75 \mu \mathrm{m}$. The synthesized powder was hot-pressed in a graphite die with an internal diameter of $10 \mathrm{~mm}$ at $898 \mathrm{~K}$ for $1 \mathrm{~h}$ under $70 \mathrm{MPa}$ in a vacuum.

The phases of the hot-pressed specimens were analyzed by $\mathrm{X}$-ray diffraction (XRD: Bruker, D8-Advance) with $\mathrm{Cu}-\mathrm{K}_{\alpha}$ radiation $(40 \mathrm{kV}$ and $30 \mathrm{~mA})$. The diffraction peaks were measured in the $\theta-2 \theta$ mode with a step size of $0.02^{\circ}$, at a scan speed of $0.4 \mathrm{~s}$ per step with irradiation at a wavelength of $0.15405 \mathrm{~nm}$. The microstructure was observed by scanning electron microscopy (SEM: FEI, Quanta400), and the chemical composition was analyzed by energy-dispersive spectroscopy (EDS: Bruker, Quantax200). The hot-pressed compacts were cut into rectangular pieces with dimensions of $3 \mathrm{~mm} \times 3 \mathrm{~mm} \times 9 \mathrm{~mm}$ to measure both the Seebeck coefficient and the electrical conductivity, and also cut into discs with dimensions of $10 \mathrm{~mm}$ (diameter) $\times 1 \mathrm{~mm}$ (thickness) to determine the thermal conductivity. Both the Seebeck coefficient and the electrical conductivity were measured with ZEM-3 (Ulvac-Riko) equipment under $\mathrm{He}$ atmosphere. The thermal conductivity $\left(\kappa=D c_{p} d\right.$ was evaluated by measuring the thermal diffusivity $(D)$, specific heat $\left(c_{p}\right)$, and density $(d)$ under vacuum using the laser flash method with a TC-9000H (Ulvac-Riko) instrument. The power factor and the dimensionless figure of merit were evaluated from the Seebeck coefficient, electrical conductivity, and thermal conductivity.

\section{RESULTS AND DISCUSSION}

Figure 1 shows the XRD patterns of the $\left(\mathrm{La}_{1-\mathrm{z}} \mathrm{Nd}_{\mathrm{z}}\right)_{0.8} \mathrm{Fe}_{4-\mathrm{x}} \mathrm{Co}_{\mathrm{X}} \mathrm{Sb}_{12}$ series. The diffraction peaks of all specimens corresponded to the standard diffraction pattern of the skutterudite phase (ICDD PDF\# 56-1123), but a small amount of the marcasite phase $\mathrm{FeSb}_{2}$ (PDF\# 70-3985) was detected. However, rareearth antimonides such as $\mathrm{LaSb}_{2}$ and $\mathrm{NdSb}_{2}$ were not produced due to the successful void filling of $\mathrm{La}$ and $\mathrm{Nd}$ in the skutterudite. The diffraction peaks for marcasite between $31.9^{\circ}$ and $32.1^{\circ}$ are enlarged in Figs. 1(b) and 1(c). Generation of the marcasite phase was suppressed by charge compensation with increasing Co content (x), and thus the 

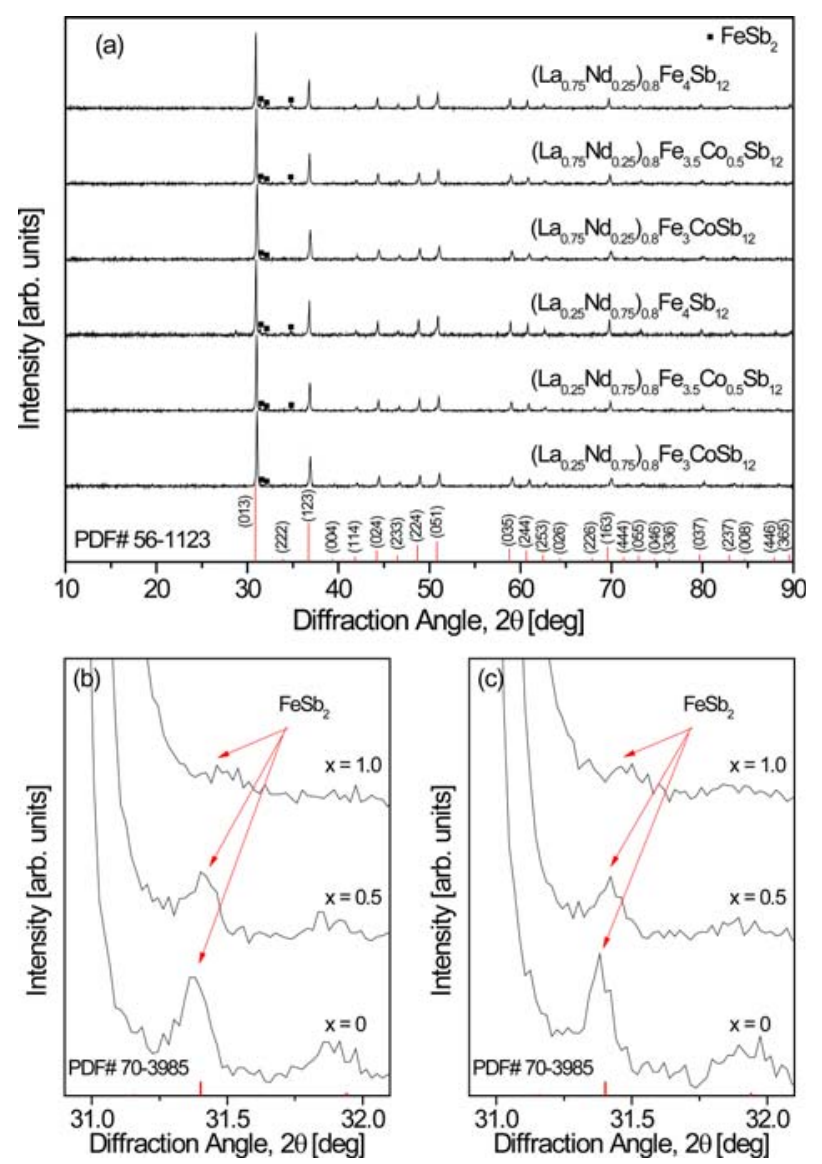

Fig. 1. XRD patterns of (a) $\left(\mathrm{La}_{1-\mathrm{z}} \mathrm{Nd}_{\mathrm{z}}\right)_{0.8} \mathrm{Fe}_{4-\mathrm{x}} \mathrm{Co}_{\mathrm{x}} \mathrm{Sb}_{12}$ skutterudites, and enlarged XRD patterns of the specimens with (b) $z=0.25$ and (c) $\mathrm{z}=0.75$. intensity of the corresponding diffraction peak decreased. In addition, the diffraction peaks shifted to higher angles with increasing Co content due to the decrease in the lattice constant because the atomic radius of Co $(0.167 \mathrm{~nm})$ is smaller than that of Fe $(0.172 \mathrm{~nm})$. Therefore, stable skutterudites were successfully synthesized by void filling with $\mathrm{La} / \mathrm{Nd}$ and $\mathrm{Co}$ charge compensation.

Figure 2 presents the scanning electron microscope (SEM) images and energy dispersive spectroscopy (EDS) line-scans for $\left(\mathrm{La}_{1-\mathrm{z}} \mathrm{Nd}_{\mathrm{z}}\right)_{0.8} \mathrm{Fe}_{4-\mathrm{x}} \mathrm{Co}_{\mathrm{x}} \mathrm{Sb}_{12}$. The marcasite phase (dark region) was formed along with the skutterudite phase (bright region). However, as the Co content increased, the signals of the $\mathrm{FeSb}_{2}$ phase became weaker. This is consistent with the $\mathrm{XRD}$ analysis. In our previous study [34], (La,Nd)Sb $\mathrm{Sb}_{2}$ phases were observed in the fully-filled $\mathrm{La}_{1-\mathrm{z}} \mathrm{Nd}_{\mathrm{z}} \mathrm{Fe}_{4-\mathrm{x}} \mathrm{Co}_{\mathrm{x}} \mathrm{Sb}_{12}$ specimens, which was attributed to exceeding the filling fraction limit. However, in the present study, it was confirmed that $(\mathrm{La}, \mathrm{Nd}) \mathrm{Sb}_{2}$ phases were not formed as the system was only partially filled.

Table 1 shows the chemical compositions, relative densities, and lattice constants of the $\left(\mathrm{La}_{1-\mathrm{z}} \mathrm{Nd}_{\mathrm{z}}\right)_{0.8} \mathrm{Fe}_{4-\mathrm{x}} \mathrm{Co}_{\mathrm{x}} \mathrm{Sb}_{12}$ samples. There was no significant change in the actual compositions after hot-pressing relative to the nominal compositions. All specimens had relative densities higher than $98.7 \%$ compared with the theoretical density. The

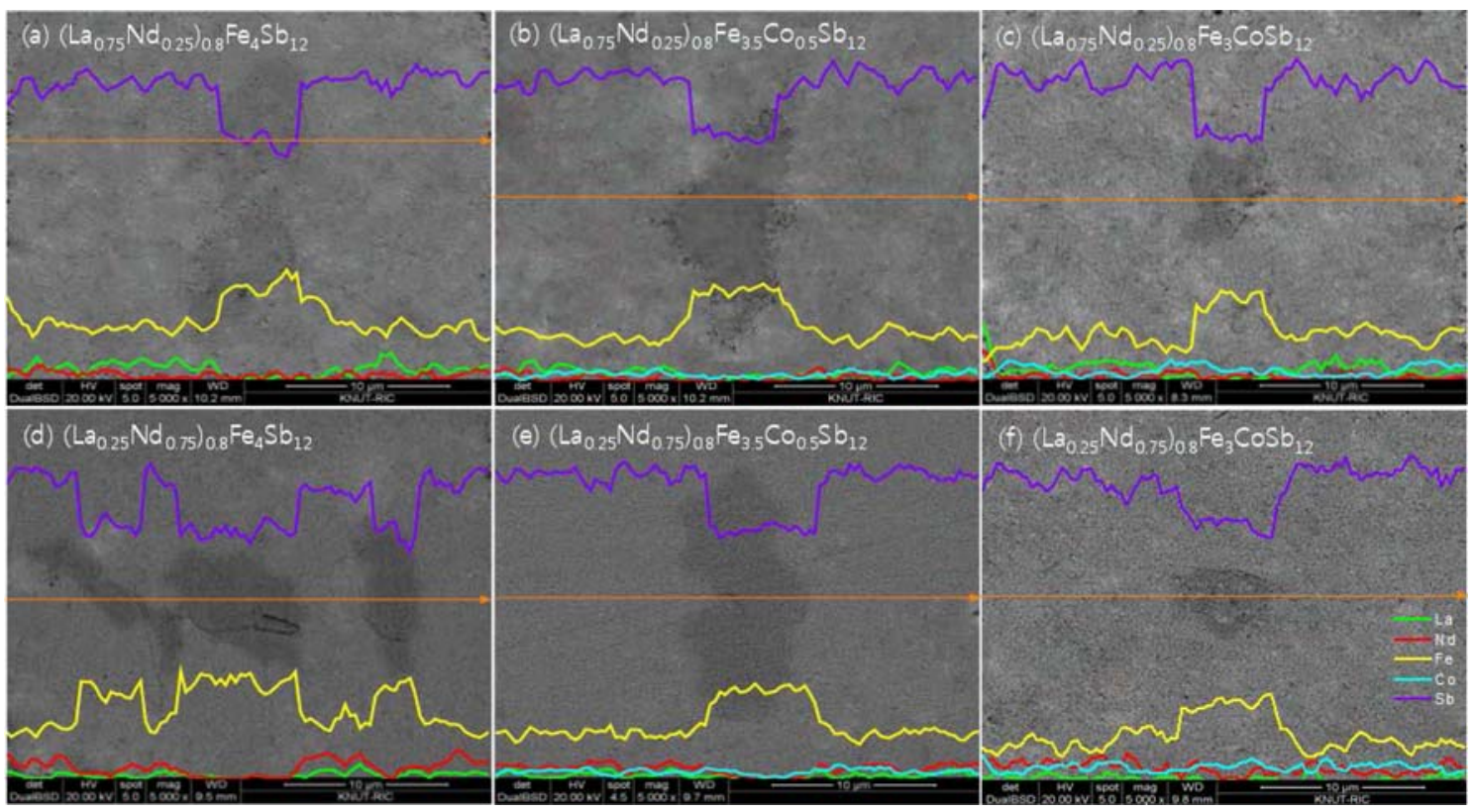

Fig. 2. $\mathrm{SEM}$ images and EDS line-scans of $\left(\mathrm{La}_{1-\mathrm{z}} \mathrm{Nd}_{\mathrm{z}}\right)_{0.8} \mathrm{Fe}_{4-\mathrm{x}} \mathrm{Co}_{\mathrm{x}} \mathrm{Sb}_{12}$. 
Table 1. Chemical compositions, relative densities, and lattice constants of $\left(\mathrm{La}_{1-\mathrm{z}} \mathrm{Nd}_{\mathrm{z}}\right)_{0.8} \mathrm{Fe}_{4-\mathrm{x}} \mathrm{Co}_{\mathrm{x}} \mathrm{Sb}_{12}$ at room temperature

\begin{tabular}{ccccc}
\hline \multicolumn{2}{c}{ Composition } & & $\begin{array}{c}\text { Relative Density } \\
{[\%]}\end{array}$ & \multicolumn{2}{c}{$\begin{array}{c}\text { Lattice Constant } \\
\text { [nm }]\end{array}$} \\
\hline$\left(\mathrm{La}_{0.75} \mathrm{Nd}_{0.25}\right)_{0.8} \mathrm{Fe}_{4} \mathrm{Sb}_{12}$ & $\mathrm{La}_{0.56} \mathrm{Nd}_{0.18} \mathrm{Fe}_{4.10} \mathrm{Sb}_{11.94}$ & & 0.9123 \\
\hline$\left(\mathrm{La}_{0.25} \mathrm{Nd}_{0.75}\right)_{0.8} \mathrm{Fe}_{4} \mathrm{Sb}_{12}$ & $\mathrm{La}_{0.19} \mathrm{Nd}_{0.55} \mathrm{Fe}_{4.11} \mathrm{Sb}_{11.92}$ & 97.5 & 0.9118 \\
\hline$\left(\mathrm{La}_{0.75} \mathrm{Nd}_{0.25}\right)_{0.8} \mathrm{Fe}_{3.5} \mathrm{Co}_{0.5} \mathrm{Sb}_{12}$ & $\mathrm{La}_{0.58} \mathrm{Nd}_{0.19} \mathrm{Fe}_{3.54} \mathrm{Co}_{0.47} \mathrm{Sb}_{11.97}$ & 99.0 & 0.9112 \\
\hline$\left(\mathrm{La}_{0.25} \mathrm{Nd}_{0.75}\right)_{0.8} \mathrm{Fe}_{3.5} \mathrm{Co}_{0.5} \mathrm{Sb}_{12}$ & $\mathrm{La}_{0.19} \mathrm{Nd}_{0.60} \mathrm{Fe}_{3.58} \mathrm{Co}_{0.48} \mathrm{Sb}_{11.97}$ & 99.1 & 0.9109 \\
\hline$\left(\mathrm{La}_{0.75} \mathrm{Nd}_{0.25}\right)_{0.8} \mathrm{Fe}_{3} \mathrm{CoSb}_{12}$ & $\mathrm{La}_{0.57} \mathrm{Nd}_{0.18} \mathrm{Fe}_{3.01} \mathrm{Co}_{1.06} \mathrm{Sb}_{11.96}$ & 98.7 & 0.9097 \\
\hline$\left(\mathrm{La}_{0.25} \mathrm{Nd}_{0.75}\right)_{0.8} \mathrm{Fe}_{3} \mathrm{CoSb}_{12}$ & $\mathrm{La}_{0.18} \mathrm{Nd}_{0.58} \mathrm{Fe}_{2.99} \mathrm{Co}_{1.04} \mathrm{Sb}_{11.94}$ & 98.5 & 0.9067 \\
\hline
\end{tabular}

calculated lattice constants ranged from 0.9067 to $0.9123 \mathrm{~nm}$ depending on the $\mathrm{La} / \mathrm{Nd}$ filling ratio and the amount of $\mathrm{Co}$ used for charge compensation. The lattice constants decreased with increasing $\mathrm{Nd}$ and Co content because the ionic radii of $\mathrm{Nd}(0.127 \mathrm{~nm})$ and $\mathrm{Co}(0.167 \mathrm{~nm})$ are smaller those of $\mathrm{La}(0.136 \mathrm{~nm})$ and $\mathrm{Fe}(0.172 \mathrm{~nm})$ [35-37].

Figure 3 presents the temperature-dependence of the electrical conductivity for $\left(\mathrm{La}_{1-\mathrm{z}} \mathrm{Nd}_{\mathrm{z}}\right)_{0.8} \mathrm{Fe}_{4-\mathrm{x}} \mathrm{Co}_{\mathrm{x}} \mathrm{Sb}_{12}$. All specimens behaved like degenerate semiconductors, showing a negative temperature-dependence of the electrical conductivity. The electrical conductivity decreased from $(1.17-2.32) \times 10^{5} \mathrm{~S} \mathrm{~m}^{-1}$ at $323 \mathrm{~K}$ to $(0.83-1.47) \times 10^{5} \mathrm{~S} \mathrm{~m}^{-1}$ at $823 \mathrm{~K}$, and decreased with increasing La and Co content in the temperature range of 323 to $823 \mathrm{~K}$. Partially filled $\left(\mathrm{La}_{0.25} \mathrm{Nd}_{0.75}\right)_{0.8} \mathrm{Fe}_{4} \mathrm{Sb}_{12}$ showed the highest electrical conductivity of $2.32 \times 10^{5} \mathrm{Sm}^{-1}$ at $323 \mathrm{~K}$. The fully-filled $\mathrm{La}_{0.25} \mathrm{Nd}_{0.75} \mathrm{Fe}_{4} \mathrm{Sb}_{12}$ exhibited a maximum electrical conductivity of $2.19 \times 10^{5} \mathrm{Sm}^{-1}$ at $323 \mathrm{~K}$ [34]. Thus, partial filling increased the electrical conductivity because fewer electrons were donated to the structure than in the case of full filling.

Figure 4 shows the temperature-dependence of the Seebeck coefficient for $\left(\mathrm{La}_{1-\mathrm{z}} \mathrm{Nd}_{\mathrm{z}}\right)_{0.8} \mathrm{Fe}_{4-\mathrm{x}} \mathrm{Co}_{\mathrm{x}} \mathrm{Sb}_{12}$. All specimens showed positive values and exhibited p-type characteristics. As the temperature increased, the Seebeck coefficient increased and then decreased at temperatures above a specific temperature. This can be explained by the relationship between the Seebeck coefficient and the carrier concentration. The Seebeck coefficient can be expressed as $\alpha=(8 / 3) \pi^{2} \mathrm{k}_{\mathrm{B}}^{2} m^{*} T e^{-1} \mathrm{~h}^{-2}(\pi / 3 n)^{2 / 3}$, where $\mathrm{k}_{\mathrm{B}}$ is the Boltzmann constant, $m^{*}$ is the effective hole mass, $e$ is the electronic charge, $h$ is Planck's constant, and $n$ is the carrier concentration. Thus, the Seebeck coefficient increased with increasing temperature, and then decreased because the carrier concentration increased dramatically

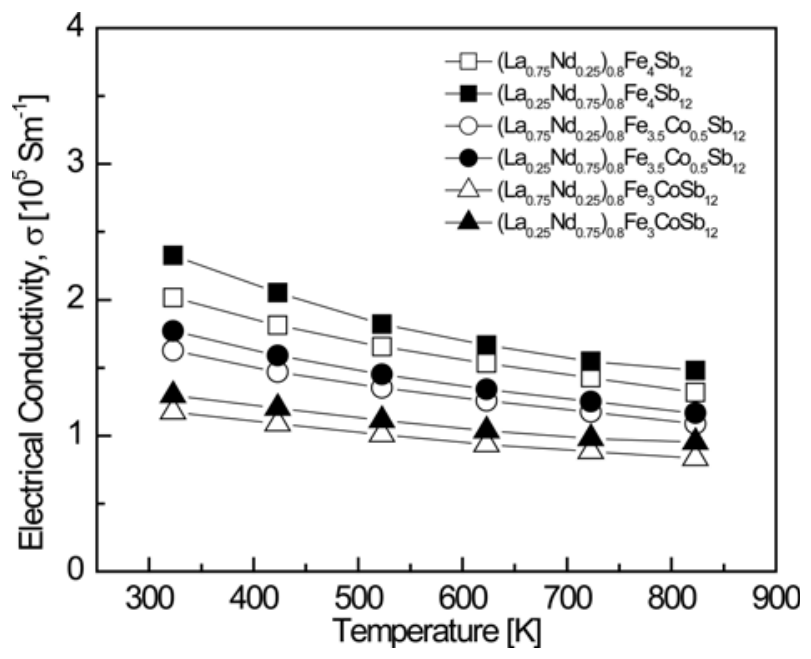

Fig. 3. Temperature-dependence of the electrical conductivity for $\left(\mathrm{La}_{1-\mathrm{z}} \mathrm{Nd}_{\mathrm{z}}\right)_{0.8} \mathrm{Fe}_{4-\mathrm{x}} \mathrm{Co}_{\mathrm{x}} \mathrm{Sb}_{12}$.

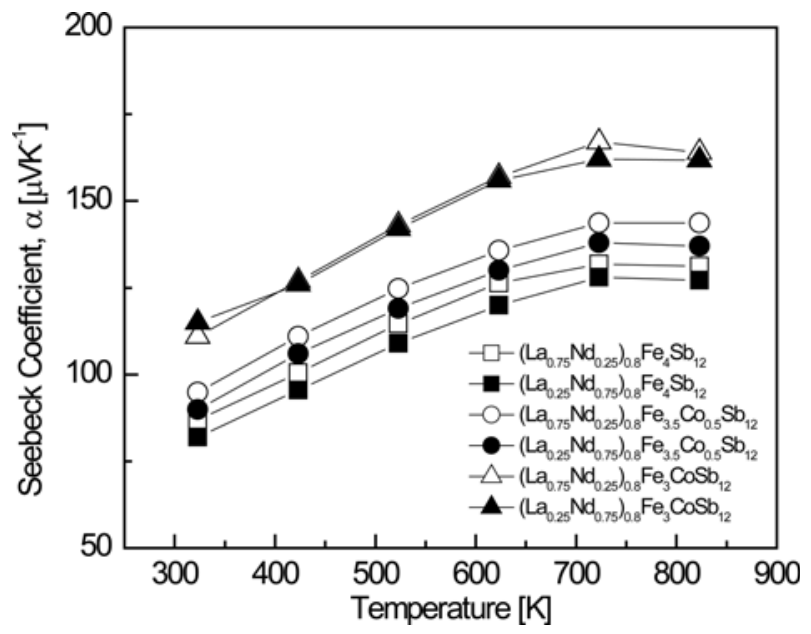

Fig. 4. Temperature-dependence of the Seebeck coefficient for $\left(\mathrm{La}_{1-\mathrm{z}} \mathrm{Nd}_{\mathrm{z}}\right)_{0.8} \mathrm{Fe}_{4-\mathrm{x}} \mathrm{Co}_{\mathrm{x}} \mathrm{Sb}_{12}$.

owing to the intrinsic transition above a specific temperature. In this study, the intrinsic transition temperature of $\left(\mathrm{La}_{1-\mathrm{z}} \mathrm{Nd}_{\mathrm{z}}\right)_{0.8} \mathrm{Fe}_{4-\mathrm{x}} \mathrm{Co}_{\mathrm{x}} \mathrm{Sb}_{12}$ was estimated to be $623-723 \mathrm{~K}$. As 
the degree of La filling and Co substitution increased, the Seebeck coefficient increased due to the decrease in the carrier concentration. Partially filled Co-doped $\left(\mathrm{La}_{0.75} \mathrm{Nd}_{0.25}\right)_{0.8} \mathrm{Fe}_{3} \mathrm{CoSb}_{12}$ showed the highest Seebeck coefficient of $167 \mu \mathrm{V} \mathrm{K}^{-1}$ at 723 K. All the fully-filled $\mathrm{La}_{1-\mathrm{z}} \mathrm{Nd}_{\mathrm{z}} \mathrm{Fe}_{4-\mathrm{x}} \mathrm{Co}_{\mathrm{x}} \mathrm{Sb}_{12}$ samples exhibited the maximum Seebeck coefficient at $823 \mathrm{~K}$, and the highest Seebeck coefficient of $164 \mu \mathrm{V} \mathrm{K}^{-1}$ at $823 \mathrm{~K}$ was achieved with $\mathrm{La}_{0.75} \mathrm{Nd}_{0.25} \mathrm{Fe}_{3.5} \mathrm{Co}_{0.5} \mathrm{Sb}_{12}$ [34]. In this study, the partially-filled specimens showed the maximum Seebeck coefficients at $723 \mathrm{~K}$, meaning that the intrinsic transition temperature shifted to lower temperatures due to partial filling.

Figure 5 presents the temperature-dependence of the power factor (PF) for $\left(\mathrm{La}_{1-\mathrm{z}} \mathrm{Nd}_{\mathrm{z}}\right)_{0.8} \mathrm{Fe}_{4-\mathrm{x}} \mathrm{Co}_{\mathrm{x}} \mathrm{Sb}_{12}$. The PF showed a peak value at a specific temperature owing to the trade-off relationship between the Seebeck coefficient and the electrical conductivity. This is because both parameters depend on the carrier concentration. The PF increased with increasing temperature, and exhibited a maximum value at temperatures between 723 and $823 \mathrm{~K}$. The PF was not significantly influenced by the $\mathrm{La} / \mathrm{Nd}$ filling ratio or the degree of Co substitution. The PF ranged from 1.43 to 2.59 $\mathrm{mW} \mathrm{m} \mathrm{m}^{-1} \mathrm{~K}^{-2}$ at temperatures from 323 to $823 \mathrm{~K}$, and the highest $\mathrm{PF}$ of $2.59 \mathrm{~mW} \mathrm{~m}^{-1} \mathrm{~K}^{-2}$ at $723 \mathrm{~K}$ was obtained with $\left(\mathrm{La}_{0.25} \mathrm{Nd}_{0.75}\right)_{0.8} \mathrm{Fe}_{3} \mathrm{CoSb}_{12}$. PF values of $1.49-2.95 \mathrm{~mW} \mathrm{~m}^{-1} \mathrm{~K}^{-2}$ were obtained for fully-filled $\mathrm{La}_{1-\mathrm{z}} \mathrm{Nd}_{\mathrm{z}} \mathrm{Fe}_{4-\mathrm{x}} \mathrm{Co}_{\mathrm{x}} \mathrm{Sb}_{12}$ at temperatures between 323 and $823 \mathrm{~K}$, and the $\mathrm{La}_{0.25} \mathrm{Nd}_{0.75} \mathrm{Fe}_{4} \mathrm{Sb}_{12}$ composition yielded the highest value of $2.95 \mathrm{~m} \mathrm{~W} \mathrm{~m}^{-1} \mathrm{~K}^{-2}$ at $823 \mathrm{~K} \mathrm{[34].} \mathrm{Therefore,} \mathrm{the} \mathrm{maximum}$ $\mathrm{PF}$ values of the fully and partially filled samples were similar, but the temperature at which the maximum $\mathrm{PF}$ appeared was lowered from 823 to $723 \mathrm{~K}$ due to partial filling.

Figure 6 shows the temperature-dependence of the thermal conductivity for $\left(\mathrm{La}_{1-\mathrm{z}} \mathrm{Nd}_{\mathrm{z}}\right)_{0.8} \mathrm{Fe}_{4-\mathrm{x}} \mathrm{Co}_{\mathrm{x}} \mathrm{Sb}_{12}$. The change in the thermal conductivity was governed by the degree of Co substitution rather than the $\mathrm{La} / \mathrm{Nd}$ filling ratio, and as the Co content increased, the thermal conductivity decreased at constant temperature. The thermal conductivity was almost constant with increasing temperature, but increased at temperatures above $623 \mathrm{~K}$ due to the bipolar effect. The thermal conductivity ranged from 2.05 to $3.95 \mathrm{~W} \mathrm{~m}^{-1} \mathrm{~K}^{-1}$ at temperatures between 323

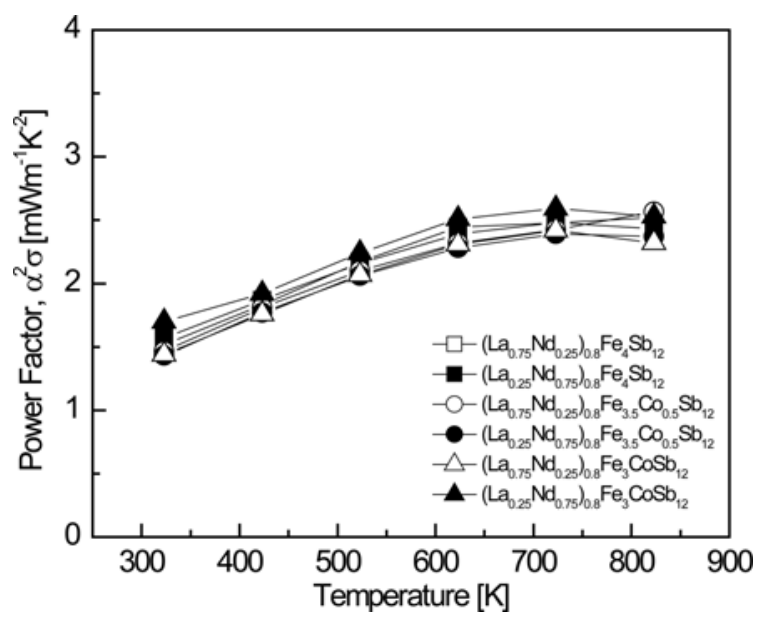

Fig. 5. Temperature-dependence of the power factor for $\left(\mathrm{La}_{1-\mathrm{z}} \mathrm{Nd}_{\mathrm{z}}\right)_{0.8} \mathrm{Fe}_{4-\mathrm{x}} \mathrm{Co}_{\mathrm{x}} \mathrm{Sb}_{12}$
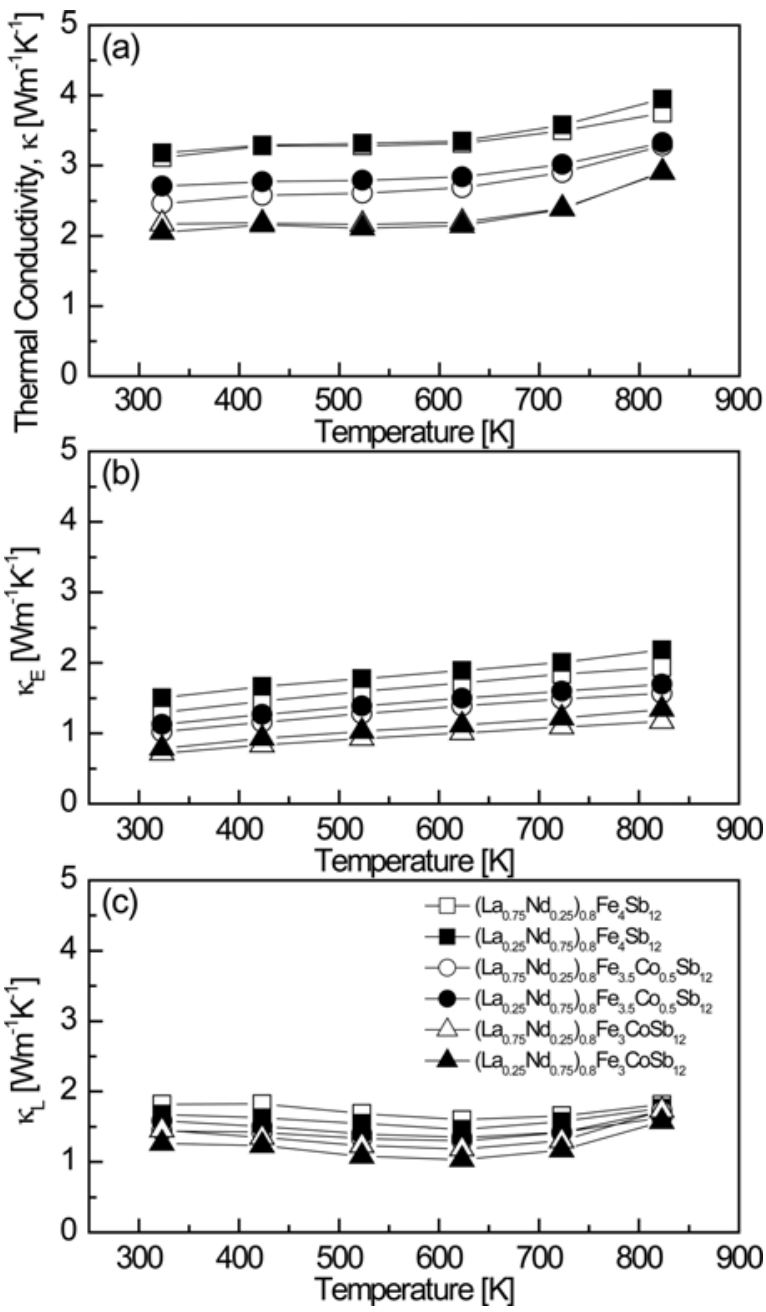

Fig. 6. Temperature-dependence of the thermal conductivity of $\left(\mathrm{La}_{1-\mathrm{z}} \mathrm{Nd}_{\mathrm{z}}\right)_{0.8} \mathrm{Fe}_{4-\mathrm{x}} \mathrm{Co}_{\mathrm{x}} \mathrm{Sb}_{12}$ : (a) total thermal conductivity, (b) electronic thermal conductivity, and (c) lattice thermal conductivity. 
and $823 \mathrm{~K}$. The $\left(\mathrm{La}_{0.25} \mathrm{Nd}_{0.75}\right)_{0.8} \mathrm{Fe}_{3} \mathrm{CoSb}_{12}$ sample exhibited the lowest thermal conductivity of $2.05 \mathrm{~W} \mathrm{~m}^{-1} \mathrm{~K}^{-1}$ at $323 \mathrm{~K}$. The thermal conductivity of the fully-filled $\mathrm{La}_{1-\mathrm{z}} \mathrm{Nd}_{\mathrm{z}} \mathrm{Fe}_{4-\mathrm{x}} \mathrm{Co}_{\mathrm{x}} \mathrm{Sb}_{12}$ samples were in the $2.07-3.01 \mathrm{~W} \mathrm{~m}^{-1} \mathrm{~K}^{-1}$ range at temperatures from 323 to $823 \mathrm{~K}$ [34]. The thermal conductivity $(\kappa)$ is the sum of the lattice thermal conductivity $\left(\kappa_{\mathrm{L}}\right)$ and the electronic thermal conductivity $\left(\kappa_{\mathrm{E}}\right)$. The $\kappa_{\mathrm{E}}$ value can be calculated from the Wiedemann-Franz law $\left(\kappa_{\mathrm{E}}\right.$ $=L \sigma T)$, where $L$ is the Lorenz number, which was taken as $2.0 \times 10^{-8} \mathrm{~V}^{2} \mathrm{~K}^{-2}$ in this study [37].

As shown in Fig. 6(b), the electronic thermal conductivity decreased with increasing Co content due to the reduction in the carrier concentration caused by Co charge compensation. The electronic thermal conductivity ranged from 0.71 to 2.18 $\mathrm{W} \mathrm{m}^{-1} \mathrm{~K}^{-1}$ at temperatures between 323 and $823 \mathrm{~K}$. $\left(\mathrm{La}_{0.75} \mathrm{Nd}_{0.25}\right)_{0.8} \mathrm{Fe}_{3} \mathrm{CoSb}_{12}$ showed the lowest electronic thermal conductivity of $0.71 \mathrm{~W} \mathrm{~m}^{-1} \mathrm{~K}^{-1}$ at $323 \mathrm{~K}$. The electronic thermal conductivity was lowest $\left(1.10 \mathrm{~W} \mathrm{~m}^{-1} \mathrm{~K}^{-1}\right.$ at $323 \mathrm{~K}$ ) for fully-filled $\mathrm{La}_{0.75} \mathrm{Nd}_{0.25} \mathrm{Fe}_{3.5} \mathrm{Co}_{0.5} \mathrm{Sb}_{12}$ [34]. As shown in Fig. 6(c), the lattice thermal conductivity was lowest for all specimens $\left(1.03-1.59 \mathrm{~W} \mathrm{~m}^{-1} \mathrm{~K}^{-1}\right)$ at $623 \mathrm{~K}$. With increasing Co substitution, the lattice thermal conductivity decreased due to enhanced phonon scattering by the impurity. However, the $\mathrm{La} / \mathrm{Nd}$ filling ratio had no significant impact on the lattice thermal conductivity. $\left(\mathrm{La}_{0.25} \mathrm{Nd}_{0.75}\right)_{0.8} \mathrm{Fe}_{3} \mathrm{CoSb}_{12}$ showed the lowest lattice thermal conductivity of $1.03 \mathrm{~W} \mathrm{~m}^{-1} \mathrm{~K}^{-1}$ at $623 \mathrm{~K}$. Fully-filled $\mathrm{La}_{1-\mathrm{z}} \mathrm{Nd}_{\mathrm{z}} \mathrm{Fe}_{4-\mathrm{x}} \mathrm{Co}_{\mathrm{x}} \mathrm{Sb}_{12}$ showed the minimum lattice thermal conductivity at temperatures between 623 and $723 \mathrm{~K}$, and $\mathrm{La}_{0.25} \mathrm{Nd}_{0.75} \mathrm{Fe}_{3.75} \mathrm{Co}_{0.25} \mathrm{Sb}_{12}$ showed the lowest value of 0.68 $\mathrm{W} \mathrm{m}^{-1} \mathrm{~K}^{-1}$ at $623 \mathrm{~K}$ [34]. Thus, partial filling slightly increased the lattice thermal conductivity. Filled skutterudites have been reported to be effective for enhancing phonon scattering as a result of low-resonance frequency scattering due to heavy filler elements or small ionic radii of the filler elements [22-26,35]. It was expected that the use of La and $\mathrm{Nd}$, which are heavy and have small ionic radii, as the filler elements would reduce the lattice thermal conductivity by improving the phonon scattering. However, the enhancement of the phonon scattering was insignificant due to the similar atomic masses and ionic radii of $\mathrm{La}$ and $\mathrm{Nd}$. As a result, the partially-filled specimens showed higher lattice thermal conductivities than the fully-filled specimens. However, the

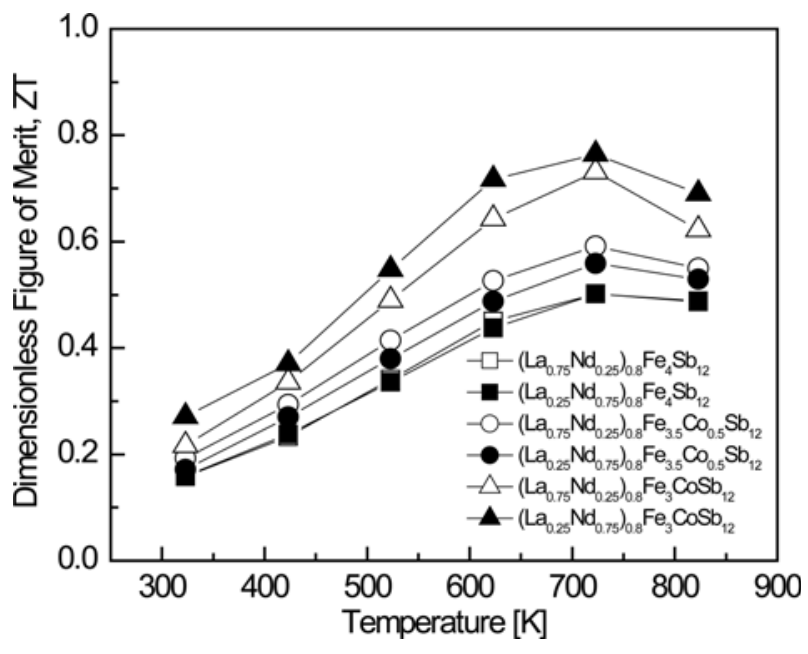

Fig. 7. Temperature-dependence of the dimensionless figure of merit for $\left(\mathrm{La}_{1-\mathrm{z}} \mathrm{Nd}_{\mathrm{z}}\right)_{0.8} \mathrm{Fe}_{4-\mathrm{x}} \mathrm{Co}_{\mathrm{x}} \mathrm{Sb}_{12}$.

electronic thermal conductivity decreased with Co charge compensation; thus, the total thermal conductivities of the partially- and fully-filled specimens were similar.

Figure 7 presents the temperature-dependence of the dimensionless figure of merit $(Z T)$ for $\left(\mathrm{La}_{1-\mathrm{z}} \mathrm{Nd}_{\mathrm{z}}\right)_{0.8} \mathrm{Fe}_{4-\mathrm{x}} \mathrm{Co}_{\mathrm{x}} \mathrm{Sb}_{12}$. The $Z T$ values increased with increasing temperature, and all specimens exhibited a maximum $Z T$ value at $723 \mathrm{~K}$. $\left(\mathrm{La}_{0.25} \mathrm{Nd}_{0.75}\right)_{0.8} \mathrm{Fe}_{3} \mathrm{CoSb}_{12}$ showed the highest $Z T$ value of 0.76 at $723 \mathrm{~K}$. However, for the fully-filled $\mathrm{La}_{0.75} \mathrm{Nd}_{0.25} \mathrm{Fe}_{4} \mathrm{Sb}_{12}$, $Z T_{\text {max }}=0.82$ at $823 \mathrm{~K}$, and for $\mathrm{La}_{0.25} \mathrm{Nd}_{0.75} \mathrm{Fe}_{3.75} \mathrm{Co}_{0.25} \mathrm{Sb}_{12}$, $Z T_{\max }=0.78$ at $723 \mathrm{~K}$ [34]. The $Z T$ values of the partiallyfilled specimens were slightly lower than those of the fullyfilled specimens. In this study, we expected to suppress the formation of secondary phases by partial double filling with $\mathrm{La}$ and $\mathrm{Nd}$, and to optimize the carrier concentration by $\mathrm{Co}$ charge compensation. In addition, we aimed to enhance the phonon scattering in order to improve the thermoelectric performance by reducing the lattice thermal conductivity. However, the improvement in the phonon scattering derived from partial double filling was insignificant due to the similar ionic radii and atomic masses of $\mathrm{La}$ and $\mathrm{Nd}$. Compared with the fully-filled specimens, the lattice thermal conductivity of the partially filled specimens was relatively high; thus, the thermoelectric performance could not be enhanced effectively. Park et al. [38] reported $Z T_{\max }=0.56$ at $823 \mathrm{~K}$ for $\mathrm{LaFe}_{4} \mathrm{Sb}_{12}$ and Shin et al. [39] obtained $Z T_{\max }=0.78$ at 823 $\mathrm{K}$ for $\mathrm{NdFe}_{4} \mathrm{Sb}_{12}$. Joo et al. [40] reported $Z T_{\text {max }}=0.74$ at 723 
$\mathrm{K}$ for $\mathrm{La}_{0.5} \mathrm{Yb}_{0.5} \mathrm{Fe}_{3} \mathrm{CoSb}_{12}$ and Shin et al. [41] attained $Z T_{\max }$ $=0.84$ at $823 \mathrm{~K}$ for $\left(\operatorname{Pr}_{0.75} \mathrm{Nd}_{0.25}\right)_{0.8} \mathrm{Fe}_{3} \mathrm{CoSb}_{12}$. Compared with these other studies, the maximum $Z T$ was achieved at lower temperatures in this study, and thus these species are expected to be applicable for thermoelectric power generation in the mid-temperature range.

\section{CONCLUSIONS}

Partially double-filled p-type $\left(\mathrm{La}_{1-\mathrm{z}} \mathrm{Nd}_{\mathrm{z}}\right)_{0.8} \mathrm{Fe}_{4-\mathrm{x}} \mathrm{Co}_{\mathrm{x}} \mathrm{Sb}_{12}$ skutterudites were synthesized by capsulated melting and subsequent sintering by hot pressing. All specimens were transformed into the skutterudite phase by annealing, but a small amount of the marcasite phase was also formed. $(\mathrm{La}, \mathrm{Nd})_{2}$ phases were not produced because the filling fraction limit was not exceeded by partial filling. The formation of marcasite was inhibited by Co charge compensation. The Seebeck coefficients were positive, indicating that all specimens had p-type characteristics. As the degree of $\mathrm{Nd}$ filling and $\mathrm{Co}$ substitution increased, the Seebeck coefficient increased and the electrical conductivity decreased due to the decreased carrier concentration. The maximum Seebeck coefficient of the partially filled specimens was achieved at lower temperature than the fullyfilled specimens. Consequently, the maximum power factor was obtained at temperatures between 723 and $823 \mathrm{~K}$, and the highest power factor of $2.59 \mathrm{~mW} \mathrm{~m}^{-1} \mathrm{~K}^{-2}$ at $723 \mathrm{~K}$ was obtained with the $\left(\mathrm{La}_{0.25} \mathrm{Nd}_{0.75}\right)_{0.8} \mathrm{Fe}_{3} \mathrm{CoSb}_{12}$ composition. No significant improvement in the phonon scattering was derived from partial double filling due to the similar ionic radii and atomic masses of $\mathrm{La}$ and $\mathrm{Nd}$. Therefore, the lattice thermal conductivity can be reduced further. $\left(\mathrm{La}_{0.25} \mathrm{Nd}_{0.75}\right)_{0.8} \mathrm{Fe}_{3} \mathrm{CoSb}_{12}$ exhibited a maximum dimensionless figure of merit, $Z T_{\max }$, of 0.76 at $723 \mathrm{~K}$.

\section{REFERENCES}

1. L. D. Zhao, V. P. Dravid, and M. G. Kanatzidis, Energy Environ. Sci. 7, 251 (2014).

2. L. E. Bell, Science 321, 1457 (2008).

3. L. D. Chen, Z. Xiong, and S. Q. Bai, J. Inorg. Mater. 25, 00561 (2010).

4. T. Caillat, A. Borshchevsky, and J. P. Fleurial, J. Appl. Phys. 80, 4442 (1996).
5. C. Sales, D. Mandrus, B. C. Chakomakos, V. Keppens, and J. R. Thompson, Phys. Rev. B 56, 15081 (1997).

6. G. A. Slack, Handbook of Thermoelectricity, edited by D. M. Rowe, p. 407, CRC, Boca Raton (1995).

7. L. D. Chen, T. Kawahara, X. F. Tang, T. Goto, T. Hirai, J. S. Dyck, W. Chen, and C. Uher, J. Appl. Phys. 90, 1864 (2001).

8. P. F. Qiu, R. H. Liu, J. Yang, X. Shi, X. Y. Huang, W. Q. Zhang, and L. D. Chen, J. Appl. Phys. 111, 023705 (2012).

9. G. Rogl and P. Rogl, Sci. Adv. Mater. 3, 517 (2011).

10. X. Shi, W. Zhang, L. D. Chen, J. Yang, and C. Uher, Phys. Rev. B 75, 235208 (2007).

11. H. Kim, M. Kaviany, J. C. Thomas, C. Uher, and B. L. Huang, Phys. Rev. Lett. 105, 265901 (2010).

12. J. Peng, J. Yang, T. Zhang, X. Song, and Y. Chen, J. Alloy. Compd. 381, 313 (2004).

13. Y. Z. Pei, L. D. Chen, W. Zhang, X. Shi, S. Q. Bai, X. Y. Zhao, Z. G. Mei, and X. Y. Li, Appl. Phys. Lett. 89, 221107 (2006).

14. X. J. Xie, J. A. He, H. J. Kang, X. F. Tang, S. Zhu, M. Laver, S. Y. Wang, J. R. D. Copley, C. M. Brown, Q. J. Zhang, and T. M. Tritt, Nano Lett. 10, 3283 (2010).

15. J. Y.u, W. Y. Zhao, P. Wei, D. G. Tang, and Q. J. Zhang. J. Electron. Mater. 41, 1414 (2012).

16. R. Carlini, A. U. Khan, R. Ricciardi, and T. Mori. J. Alloy. Compd. 655, 321 (2016).

17. R. Liu, J. Y. Cho, J. Yang, W. Zhang, and L. Chen. J. Mater. Sci. 30, 1134 (2014).

18. X. F. Tang, L. D. Chen, T. Goto, T. Hirai, and R. Z. Yuan. J. Mater. Sci. 36, 5435 (2001)

19. A. J. Minnich, M. S. Dresselhaus, Z. F. Ren, and G. Chen, Energy Environ. Sci. 2, 466 (2009).

20. D. T. Morelli and G. P. Meisner, J. Appl. Phys. 77, 3777 (1995).

21. G. S. Nolas, J. L. Cohn, and G. A. Slack, Phys. Rev. B 58, 164 (1998).

22. Y. E. Cha and I. H. Kim, Korean J. Met. Mater. 56, 465 (2018).

23. Q. Li, Z. W. Lin, and J. Zhou, J. Electron. Mater. 38, 1268 (2009).

24. X. Shi, J. Yang, J. R. Salvador, M. F. Chi, J. Y. Cho, H. Wang, S. Q. Bai, J. H. Yang, W. Q. Zhang, and L. D. Chen, J. Am. Chem. Soc. 133, 7837 (2011).

25. J. Yang, W. Zhang, S. Q. Bai, Z. Mei, and L. D. Chen, Appl. Phys. Lett. 90, 192111 (2007).

26. X. Shi, S. Q. Bai, L. L. Xi, J. O. Yang, W. Q. Zhang, L. D. 
Chen, and J. Yang, J. Mater. Res. 26, 1745 (2011).

27. G. Rogl, A. Grytsiv, P. Rogl, E. Bauer, and M. Zehetbauer, Intermetallics 19, 546 (2010).

28. G. P. Meisner, D. T. Morelli, S. Hu, J. Yang, and C. Uher, Phys. Rev. Lett. 80, 3551 (1998).

29. B. X. Chen, J. H. Xu, C. Uher, D. T. Morelli, G. P. Meisner, J. P. Fleurial, T. Caillat, and A. Borshchevsky, Phys. Rev. B $\mathbf{5 5}, 1476$ (1997).

30. S. Ballikaya, N. Uzar, S. Yildirim, H. Chi, X. L. Su, G. J. Tan, X. F. Tang, and C. Uher, J. Electron. Mater. 42, 1622 (2013).

31. G. Rogl, A. Grytsiv, E. Bauer, P. Rogl, and M. Zehetbauer, Intermetallics 18, 57 (2010).

32. G. Rogl, A. Grytsiv, M. Falmbigl, E. Bauer, P. Rogl, M. Zehetbauer, and Y. Gelbstein, J. Alloy. Compd. 537, 242 (2012).

33. X. Meng, W. Cai, Z. Liu, J. Li, H. Geng, and J. Sui, Acta
Mater. 98, 405 (2015).

34. K. M. Song, D. K. Shin, and I. H. Kim, J. Korean Phys. Soc. 67, 1597 (2015).

35. P. F. Qiu, J. Yang, R. H. Liu, X. Shi, X. Y. Huang, G. J. Snyder, W. Zhang, and L. D. Chen, J. Appl. Phys. 109, 063713 (2011).

36. R. D. Shannon, Acta Cryst. A 32, 751 (1976).

37. G. J. Tan, S. Y. Wang, G. Yan, H. Li, and X. F. Tang, J. Electron. Mater. 41, 1147 (2012).

38. K. H. Park, I. H. Kim, S. M. Choi, Y. S. Lim, W. S. Seo, and K. H. Kim, Jpn. J. Appl. Phys. 52, 10MB18 (2013).

39. D. K. Shin and I. H. Kim, J. Electron. Mater. 45, 1234 (2016).

40. G. S. Joo, D. K. Shin, and I. H. Kim, J. Electron. Mater. 44, 1383 (2015).

41. D. K. Shin and I. H. Kim, J. Korean Phys. Soc. 69, 798 (2016). 